served, their memory rank in its decadence much more frequently exceeded the study rank than among the whites-an excess also due to their acknowledged racial deficiency in reasoning power.

The intellectual deficiency of the blacks as compared with the whites is more particularly shown by the average ages at which the grades were attained by both races; the blacks having attained the fourth grade at 12 years, and the fifth grade at 13.14 years, while the whites attained the fourth grade at 10.63 years, and the fifth at $I 1.40$ years, a difference in favor of the whites of 1.37 years in the fourth, and of 1.74 years in the fifth grade, differences which indicate the value of heredity in racial culture even if ability to memorize be equal.

It is not within the purpose of this paper to deal with educational methods, but rather with results.

In studying the latter, it is painfully apparent " that the fundamental, discouraging and almost insurmountable difficulty in the education of the Negro is his ignorance of our language; in his home and in the field, in the church and school, he speaks a patois without a literature, and with a very limited vocabulary. The great mass of the Negro population of the country very rarely hears the English language spoken in its purity, and the children fortunate enough to be taught by one of their race who has acquired it, only hear it in the school room or in the houses of their white masters." (Article, 'The Negro and the Church,' by the writer, Prot. Epis. Rev., July, 1896.) In both races there is a better knowledge of the signs or symbols than of the things signified, or an imperfect mastery of the language. Among the blacks, it will especially be found that many words in very simple prose and verse convey no conception of the thought or object represented. They also exhibit a decadence of the observing faculties from earlier conditions.

In both races there is a too great reliance on exterior aids, and a neglect, deficiency, or failure in habits of thought or the ability to think clearly, which makes it difficult for a child to use its own natural mental gifts, and which ultimately results in a loss of brain power and an inability to assimilate, or to determine the general principles to be derived from the great variety of particular knowledge presented in our school curricula. GeORGE R. STETSON.

WASHINGTON, D. C.

\title{
EXPERIMENTS ON MEMORY TYPES.
}

It has been said that "the great mystery of memory lies in the mind's apparent power to transcend time and bring itself into contact 
with the vanished past." It is not the purpose of the present paper to solve the ' mystery of memory,' but to show how memory, under certain conditions, acts. This article will give the results of experiments tried upon auditory and visual memory.

Auditory-Memory. The following experiment was tried on public school children, students in a commercial school, and juniors and seniors in a college. Three groups of numbers were chosen, each group consisting of ten numbers. The first group was read at the rate of one number per second. The second group was read twice, and the third group three times, each number being pronounced at the same rate as those of the first group.

The purpose of the experiment was to find how much the memory would be strengthened by the second and third reading. The experiment was tried several times upon a class of seventh grade pupils and the results were as follows: They numbered $52 \%$ of the total number with one reading; $50 \%$ with two readings, and $58 \%$ with three readings. Sixth grade pupils gave the following: $42 \%$ of the total number with one reading, $4 \mathrm{r} \%$ with two, and $54 \%$ with three readings. The experiment tried upon the commercial students varied a little from the sixth and seventh grade pupils, giving these results: one reading $36 \%$ of total number; two readings $37 \%$, and $54 \%$ with three readings. The experiment which was tried upon a class in psychology at San José College, gave the following results: One reading $58 \%$ of total number; $44 \%$ of total number with two readings, and $66 \%$ of entire group with three readings. Some results obtained from a class in psychology at Napa College were as follows: $48 \%$ of total number with one reading, $40 \%$ with two readings, and $65 \%$ with three readings; or, to put them in tabular form, they would be as follows :

\begin{tabular}{lccc}
\multicolumn{1}{c}{ Class. } & I. & II. & III. \\
7th Grade. & .52 & .50 & .58 \\
6th ،6 & .42 & .41 & .54 \\
Com. Stud't. & .36 & .37 & .54 \\
S. J. C. & .58 & .44 & .66 \\
N. C. & .48 & .40 & .65
\end{tabular}

These figures seem to indicate that two readings nearly alwaysthere being but one exception-weakens the memory. I noticed in trying the experiment that after the group was pronounced once and was being pronounced again there nearly always appeared a look of confusion in the faces of the pupils. In the first reading associations 
would be formed, associating certain numbers together and giving them a certain order, such as might be suggested as they were being read. But, when they were read the second time, new associations would be formed, and some of the former ones lost, thus making a confusion in their thought and causing them to lose all the associations they had made.

In every case there was a decided improvement with three readings. This may be because the third reading harmonized the associations made in the two previous readings and thus the confusion that was caused was dispelled.

The data obtained shows that the power of retaining or recalling the memory-image varies with different persons. Some were able to recall the entire list while others could only recall two or three numbers. But the fact that one person is better than another in reproducing memory-images, it does not indicate that he has a better mind, as is thought by some people. Usually the boy or girl with a 'parrotlike memory' pleases everybody, while he who has to cognate and con over what he wishes to remember does not stand very high in the popular estimation.

It was found that younger pupils nearly always reproduce the numbers without any hesitation, while college students always hesitated and required more time to reproduce the list. This would seem to indicate that pure spontaneous memory depends on the degree of impressibility, while a cultured intellect depends more upon the power of reason. Young children are superior to men in impressibility, in the power of retaining the memory-image, and in spontaneous recollection, while the latter have gained more power of voluntary acquisition and recollection. Hence the training of memory should not only be to increase the power to recall an image, but the power to determine what shall be recalled.

Some experiments seem to indicate that the power of recognition is nearly double that of recall, that is, if some of the numbers not reproduced be mentioned, they are recognized in nearly every instance.

Visual-Memory. Two lists of words, consisting of fifteen each, were chosen, care being taken in the arrangement of the words.

They were as follows:

I.

Bottle

Pen
II.

Table

Man 
I.

Coat

Floor

Gun

Picture

Stove

Ring

Tree

House

Rock

Sun

Bridge

Hill

Chair
II.

Book

Room

Cat

Desk

Spade

Ship

Knife

Carpet

Lamp

Pencil

Window

Fan

Mouse.

The two lists were placed upon the blackboard and covered. The cover was taken from the first list and it was exposed for thirty seconds. The second list was exposed at the rate of one word every two seconds, the word being erased at the end of that time.

The object of the experiment was to determine which was stronger, successive or simultaneous memory.

It was tried upon pupils of a public school, ranging from eight to fifteen years of age, and the following results were obtained:

$\begin{array}{ccc}\text { Age. } & \text { Sim. } & \text { Suc. } \\ 8 & .11 & .33 \\ 9 & .32 & .49 \\ 10 & .33 & .49 \\ \text { I1 } & .44 & .52 \\ 12 & .55 & .56 \\ 13 & .53 & .54 \\ 14 & .56 & .56 \\ 15 & .51 & .52\end{array}$

The table seems to indicate that successive visual-memory is much better for the younger pupils than simultaneous visual-memory; but as they increase in age they improve in the power of the latter, there being a difference of $22 \%$ at the age of eight, while there is a difference of only one per cent at the age of fifteen.

It will be noticed that the increase in the power of recall is not uniform throughout, those thirteen years of age being below those of twelve, and those fifteen less than those of fourteen. This is owing 
to some idiosyncrasies of the individual pupils, but does not effect the general result.

The reason the younger pupils recall more of the second group is, probably, because their power of association is not so great. Their power of reproducing the words depends upon their powers of retention and the degree of impressibility, while the older pupils depend more upon association for retaining the words and their volitional powers to recall them. In the second group the opportunity offered for association is not so great as in the first, and hence, more are remembered by the younger pupils.

A similar experiment was tried on a class of commercial students, but numbers were used instead of words. They varied from fifteen to twenty years in age, and it was found that simultaneous was much stronger for them than successive visual-memory, there being $42 \%$ of the entire list reproduced when the fifteen numbers were exposed thirty seconds, and $39 \%$ when each number was exposed two seconds.

This seems to indicate that older students and those more advanced can recall more objects when exposed simultaneously than when shown successively. It is owing to the fact that the power of association is stronger in the older than in younger persons.

Visual-and Auditory-Memory. This experiment was tried on public school children. Two groups of names were used, each group consisting of ten words. The first group was read at the rate of one word every two seconds. The other group was placed on the blackboard and covered. Each word was then uncovered at the rate of one every two seconds and erased at the end of that time.

The object of the experiment was to determine which was the stronger, visual or auditory-memory.

The data obtained seems to indicate that generally auditory-memory is much stronger for younger pupils than visual-memory. The following results were obtained :

$\begin{array}{rcc}\text { Age. } & \text { Auditory. } & \text { Visual. } \\ 8 & .42 & .30 \\ 9 & .54 & .57 \\ \text { 10 } & .57 & .54 \\ \text { I } & .69 & .66 \\ \text { 12 } & .80 & .65\end{array}$

There is but one instance in the above table where the visualmemory excels the auditory, and this was probably due to a lack of attention by a few pupils. 
The younger children are accustomed to a large amount of auditory work, and it is natural that they should remember spoken better than written words.

It is probably true that the auditory-memory is associated with the visual. I noticed, in trying the experiment upon some pupils, that they pronounced the words softly as they were exposed. Thus, if "when the two senses act together in recollection they hinder each other," we must observe this in accounting for the fact that visual is weaker than auditory-memory.

A similar experiment was tried upon a class of commercial students, ranging from fifteen to twenty years in age, gives $28 \%$ of the total number reproduced in auditory and $45 \%$ in visual-memory. This would seem to indicate that visual-memory is better for older students than auditory-memory. The reason is because visual-memory is employed more by them than auditory.

Yale UNIVERSITY.

Chauncey J. Hawkins.

\section{THE PROPAGATION OF MEMORIES.}

One essential condition of the continuity of individual consciousness in our present state seems to be the persistence of impressions in the substrate, or, in other words, the retention of vestiges. It is apparently usually implied, if not stated, that this persistence is due to the survival of the cells (of the cortex presumably) in which the original impression issuing in consciousness was made. Were this theory correct the destruction of a given cell or generation of cells would banish forever their vestiges and destroy the power of reproduction in so far. It is, however, a notorious fact that the events of a very early period of life are remembered and vividly conceived of even in very late life, and it is not unusual for the earlier events or experiences to crowd out the later ones which ought, by reason of their freshness, to be most prominent. Any theory of memory which depends on the persistence of the original elements is weak, in view of the theoretical consideration mentioned, and is contradicted by facts of observation. In the first place, the law of substitution and restoration of function is well intrenched in the data of pathology and experiment, and, in the second, we have every reason to believe that the individual cell of the cortex has its birth, adolescence and period of decline, like any other cell, and it follows that its vestiges, as such, disappear with it. 